\title{
Concept of scale in marine ecology: linking the words or the worlds?
}

\author{
Andrey I. Azovsky
}

\begin{abstract}
Azovsky, A. I. 2000. Concept of scale in marine ecology: linking the words or the worlds? - Web Ecol. 1: 28-34.

The concept of scale (in sensu lato) is considered to be very promising as the integrative basis for modern ecology. Nowadays it is not a full-blown theory but rather a flexible and progressively developing methodology to outline future unifying theories. It provides a powerful conceptual framework for generating testable hypotheses and studying a wide range of ecological phenomena related with such themes as heterogeneity, hierarchy and size. Spatio-temporal heterogeneity, organizational hierarchies and body size are the main scaling factors for ecological patterns and processes. Broad comparison of patterns for these three different but interrelated dimensions can reveal some new regularities ("scaling laws") of ecological systems. It also allows us to look at the worlds of different organisms "through their own eyes". Some examples of applying the crossscaling approach in marine ecology are considered: - Patterns and scales of spatial heterogeneity; - Species-area curves and body size; - Co-occurrence of congeners as scaledependent phenomenon; - Spatio-temporal ranges of ecological hierarchies.
\end{abstract}

\section{A. I. Azovsky (azovsky@1.hydro.bio.msu.ru), Dept of Hydrobiology, Biology Faculty, Mos- cow State University, Moscow 119899 Russia.}

One of the main problems of modern ecology, from my point of view, is the great gap between the "primary production" of data and its' theoretical "assimilation". As far back as three decades ago MacArthur (1968) called on ecologists to seek generalized principles: "Ecological patterns, about which we construct theories, are only interesting if they are repeated. They may be repeated in space or time, and they may be repeated from species to species. A pattern... which has repetition is of special interest, because of its generality...”. In other words, we should seek out the general patterns in our data, linking them to the general ideas produced by theorists.

Among the many possible ways of making such a synthesis, the concept of scale seems to be very promising as the integrative basis for modern ecology. It is not yet a fullblown theory but rather a flexible and progressively devel- oping methodology to outline future unifying theories. It provides a powerful conceptual framework for describing a wide range of ecological phenomena and generating testable hypotheses (see recent reviews: Levin 1992, Shneider 1994, Peterson and Parker 1998).

The notion of scale (in sensu lato) is quite broad and covers many other concepts which could be "clustered" by key terms such as heterogeneity, hierarchy and size (Fig.1). The first one, including both spatial patchiness and variability in time, is now recognized as an essential property of nature (Kolasa and Pickett 1991). Furthermore, ecological systems are always hierarchically organized (O'Neill et al. 1986, Kolasa 1989) and this forces us to consider an organizational scale. Lastly, the evident size-dependence of species' features (Peters 1983) adds one further scaling axis to the general picture. Spatio-temporal heterogeneity, or- 
TERMS AND DIMENSIONS OF SCALING:

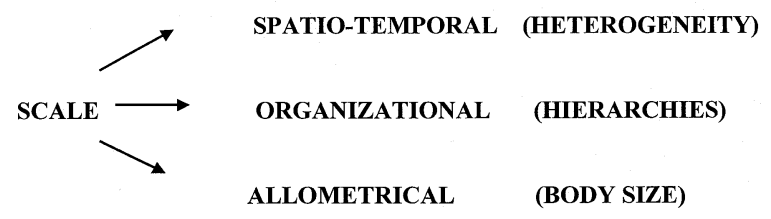

Fig. 1. Main scaling dimensions in ecology and related terms.

ganizational hierarchies and size allometry are the main scaling factors for ecological patterns and processes.

Here we face the difficult problem of linking all these factors, or dimensions, to answer how space and time are arranged for living things. The more interesting findings are expected from comparative studies in several such dimensions. Below I shall briefly give a few selected examples where such a cross-scaling approach uncovers some simple but rather nontrivial regularities. The aim of the article is to attract the reader's attention to some key aspects and to provoke further discussion, rather than to present the results of any particular study. The paper is deliberately speculative, and it should be read in that spirit.

\section{Patterns and scales of spatial heterogeneity}

The first example concerns spatial heterogeneity and involves the size of organisms as scaling factor. The "total" heterogeneity of nature is widely acknowledged known: all ecological structures are heterogeneous at a broad range of (perhaps at any) scales. As a rule, the wider range of scales one considers, the more levels of patchiness are recognized with some hierarchical order. The fact seems trivial now, but are there any regularities in this irregularity, and if so, what are their reasons? This question, a central one for comprehending this changeable mosaic as a whole picture, goes to the heart of the problem of scale (Kolasa and Pickett 1991).

We have studied the distribution of soft-bottom intertidal communities (Azovsky and Chertoprood 1997, Chertoprood and Azovsky 2000, Azovsky et al. 2000) and found different types of patterns changing along the scale of study (Fig. 2a). At small scale there is mosaic of randomly arranged micropatches without any obvious autocorrelation, i.e. average structural similarity of every two points sampled at this scale does not depend on the distance between them. Then it gives way to a nested hierarchy of patches. This range is particularly noteworthy, because the distribution there not only has several levels of patchiness, but also demonstrates noticeable self-similarity (Azovsky and Chertoprood 1997, 1998, Azovsky et al. 2000). Thus, we couldn't pick out any specific scale of spatial variability a

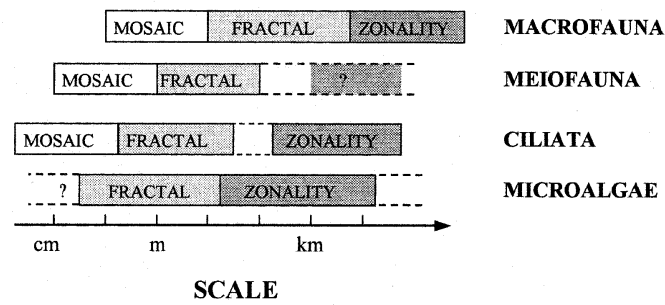

b

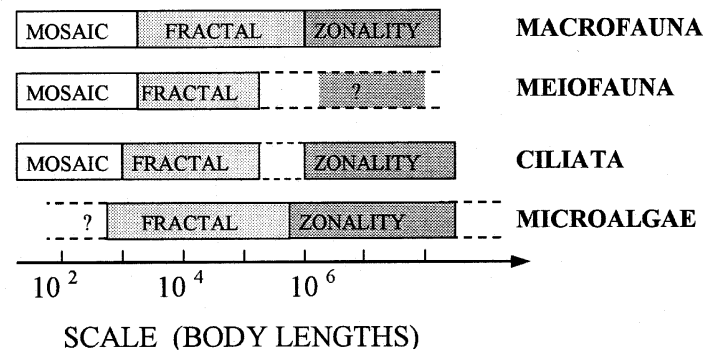

Fig. 2. Spatial ranges of different distribution patterns for various groups of intertidal benthos (axis is logarithmic).

for such fractal-like patterns: they look equally heterogeneous at a range of scales! These fractal-like patterns, in turn, change to large-scale zonality or gradients. It is particularly interesting that this order (random mosaic - fractal patchiness - gradient) remains for all the groups studied - from microalgae and ciliates to macrofauna, but the ranges occupied by patterns of different kinds correlate with organisms' body size. The boundaries coincide well if spatial dimension is allometrically rescaled (Fig. 2b). It should be noticed, however, that the real transitions are rather gradual, without any obvious cut-offs, so the ranges shown here are rather rough estimates. The demarcations were made by comparing a number of nested sample sets at different extent and resolution (Chertoprood and Azovsky 2000, Azovsky et al. 2000).

Three relative levels could be tentatively distinguished in this complex patterns, all defined generally as regions that are more-or-less homogeneous with respect to a species composition. Patches - smallest elements of mosaic, which appear due to local predominance of one or other species. Adjacent set (sometimes - fractal) of the patches I define as a Local community - an area with a common set of dominant species. Collection of such local communities forms a Type of community - a certain set of the life-forms occupying some certain type of habitat (the similar notions are the "parallel communities" of Thorson (1958), or associations in phytocenology). Following this way, let us now add a time dimension to this hierarchy. Using both original and literature data, we approximately estimated the corresponding ranges (as the typical sizes and times of existence) for both micro- and macrofauna, from single patches to community types. The "life-span" for these units shows how long they hold their specific composition and position, and reflects their dynamics: rate of move- 
ment and life history - for the patches, rate of succession for communities (Burkovsky et al. 1994, Azovsky and Mokievsky 1996). It is clear that spatio-temporal scales for ciliates, looking through a human eye, are rather smaller than for macroorganisms (Fig. 3a). But animals perceive neither distances in meters nor time in weeks! Let's convert them from metric to ecological units: space - in body sizes, and time - in generations. After such rescaling, the corresponding domains match closely (Fig. 3b). Recently Holling (1992) showed that terrestrial vertebrates also "measure" their environment and "make their decisions" with grain defined as a function of their size. So we can say that different groups are guided by the unified plan of world-creation but use their own measures to create it!
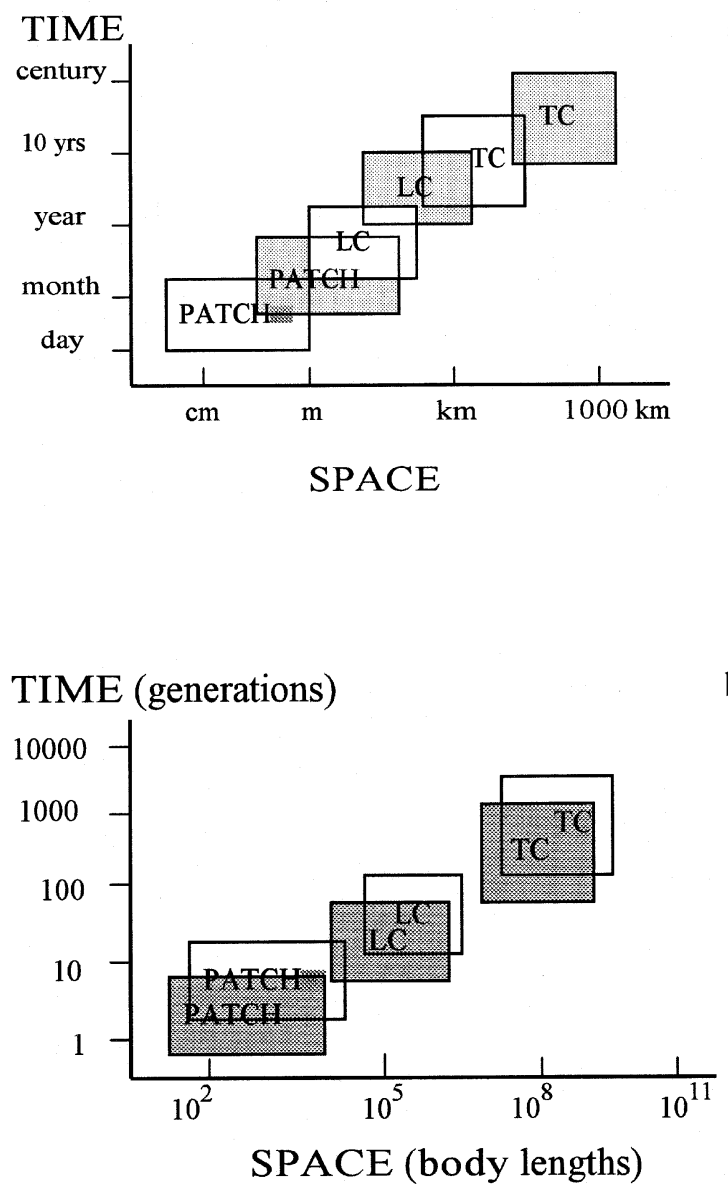

Fig. 3. Spatio-temporal ranges occupied by various entities of micro- (open) and macrofauna (shaded). PATCH: micropatches, LC: local community, TC: community type.

\section{Species-area curves and body size}

Another size-scaling rule could be found in well-known species-area relations. It has been noted that the smaller the organisms are, the more widespread or cosmopolitan forms are among them (Fenchel 1993, May 1994, Finlay et al. 1996). However, robust numerical analyses of differences in biodiversity trends are scarce because of the difficulties in obtaining comparable data for different groups. In Fig. 4, data on species richness are presented for some groups of the Arctic benthos. The data pool (both original and compiled from a number of sources) covers a wide range of areas from single samples to the whole seas. To make the graphs comparable, the values are expressed as a percentage of total species number in the group. We can see that the number of small species (ciliates and diatom algae) does increase more slowly than the number of bigger ones. The slopes estimated by log-linear regression appear to depend strongly on the average body size (Fig. 5). The similar results were obtained for zooplankton (McGowan 1971). Thus, both $\alpha$ - and $\beta$-components of species divera sity are size-dependent, at least for aquatic communities. As a consequence, the actual relations between species numbers and their physical size are spatially scale-dependent: there are many more species in smaller size classes in any one local community, but at a global scope the situation changes drastically (Fenchel 1993, Finlay et al. 1999). To understand fully the species diversity patterns we should consider properly how the species measure their habitat diversity. Phylogenetic considerations (e.g., evolutionary age) could also be important (Tchesunov 1981). And again, body size appears here as the key scaling factor. It would be rather interesting to test the similar patterns for land ecosystems.

\section{Co-occurrence of congeners as scale- dependent phenomenon}

Some patterns which look random at a one single scale might show up regularities when different scales are compared. To illustrate this fact I consider the problem of cooccurrence of taxonomically related species. Should congener species be found living together more frequently because of their common ecological requirements? Or, conversely, should they exclude each other because of strong competition, as it follows from the Gause Law (Gause 1934)? These two opposite views are the subject of keen debates, and data used to support each argument are rather controversial (Den Boer 1985, Connor and Bovers 1987, Azovsky 1992). I reconsidered the issue, treating the distribution of congeners as a statistical phenomenon in terms of null-hypotheses testing and taking into account the scale of examination (Azovsky 1992, 1996). For various groups (marine Ciliata and Polychaeta, fresh-water Gastropoda and terrestrial Carabidae beetles), observed probabili- 


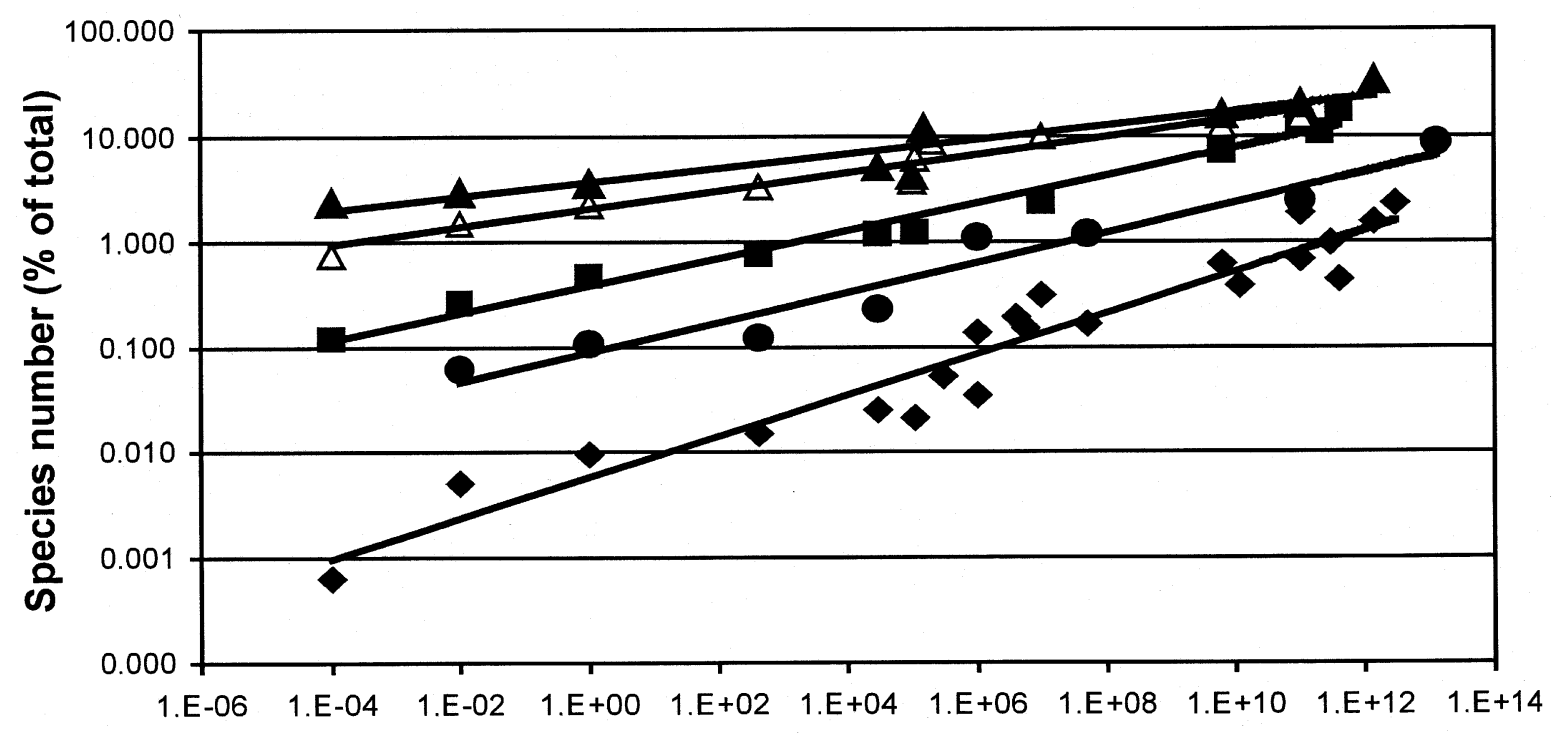

\section{Area $\left(\mathrm{m}^{2}\right)$}

Fig. 4. Species-area curves for various groups of Arctic benthos (both axes are logarithmic). $\downarrow$ : All macrofauna, Diatomea, $\triangle$ : Ciliata, $\mathbf{\square}:$ Nematoda.

ties of co-occurrence for congeners were compared with the expected values. The analysis was made separately at different scales: for local data sets (communities or single samples), for combined sets (habitat types or regional faunas) and for "global" data (total species lists or sea faunas). I found that taxonomically related species do tend to coexist at large scale choosing the same regions or macrohabitats. However, they often replace each other at local scale, occupying different sites, microhabitats or niches. The superimposition of both these tendencies just could result in mosaic patterns of species occurrence. At "biogeographic" level (fauna of particular seas and oceans as samples from the World Ocean fauna), the congener species were found together no more frequently than expected. I treated these patterns as result of combined effect of the main factors determining the species presence/ab-

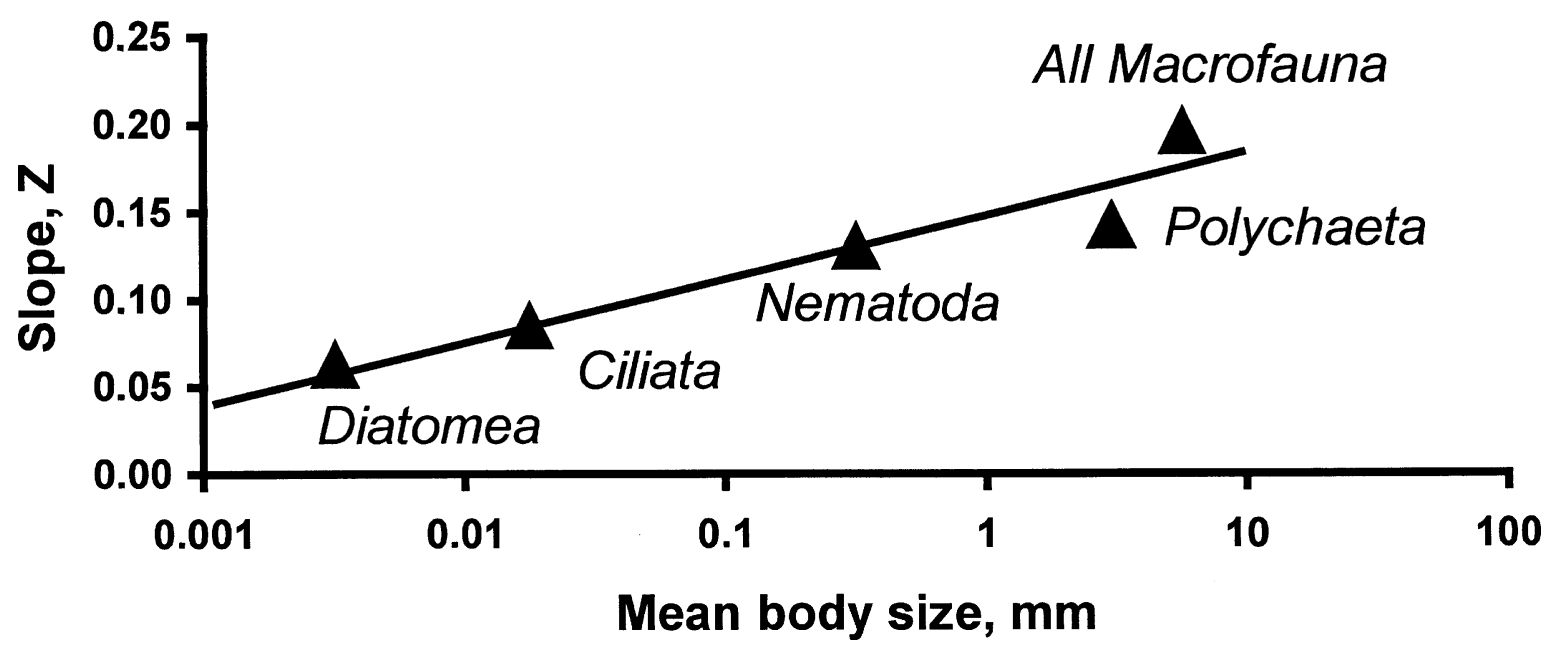

Fig. 5. Species/area curve slopes as function of mean individual body size $\left(\mathrm{R}^{2}=0.91\right)$. 
sence: biotic (competition) - at local scale, abiotic (environmental requirements) - at regional scale, and evolutionary ones (speciation, extinction) - at biogeographical scale (Fig. 6). Thus, in fact the controversy between coexistence and exclusion principles proves imaginary. Both principles can coexist perfectly while operating at the proper scales.

\section{Spatio-temporal ranges of ecological hierarchies}

The last, more general example concerns the spatio-temporal ranges of ecological hierarchies. Ecologists study complex systems that span many levels of organization and hence can be viewed as discrete hierarchical entities. Entities of each level have some specific spatio-temporal ranges of functioning, and connections between them are effected by some integrative processes of energy, matter or information transfer (Urban et al. 1987, Kolasa 1989). The nature of the integrative processes determines the mode of linking the levels of organization in the hierarchy.
There are several ways to build such hierarchies, and a number of them have been described for various kinds of patterns or processes. One of the best-known examples is known as Stommell's diagram and presents the characteristic scales of plankton variability: from micropatches up to biogeographical provinces and oceanic fronts (Haury et al. 1978). Similar "Stommel' diagrams" were recently presented both for terrestrial (Holling 1992) and benthic (Azovsky and Mokievsky 1996, Fig.3 in this article) communities. Some other examples for vegetation patterns and processes from leaf to landscape were given by Urban et al. (1987). On each level of a hierarchy, the units could be characterized by certain specific ranges: spatial (as an area occupied by pattern or involved into the process) and temporal (as span of existence or development).

Regardless of the nature of hierarchy, the spatial and temporal scales of its levels are closely correlated. I compare the average time and space ranges of different units reported for some hierarchical systems (Table 1) and have found good correlations between both scales. The idea of coupling these scales is certainly not new in general, but I would like to draw attention to some special points. First of all, there is a wonderful similarity in the form of scaling
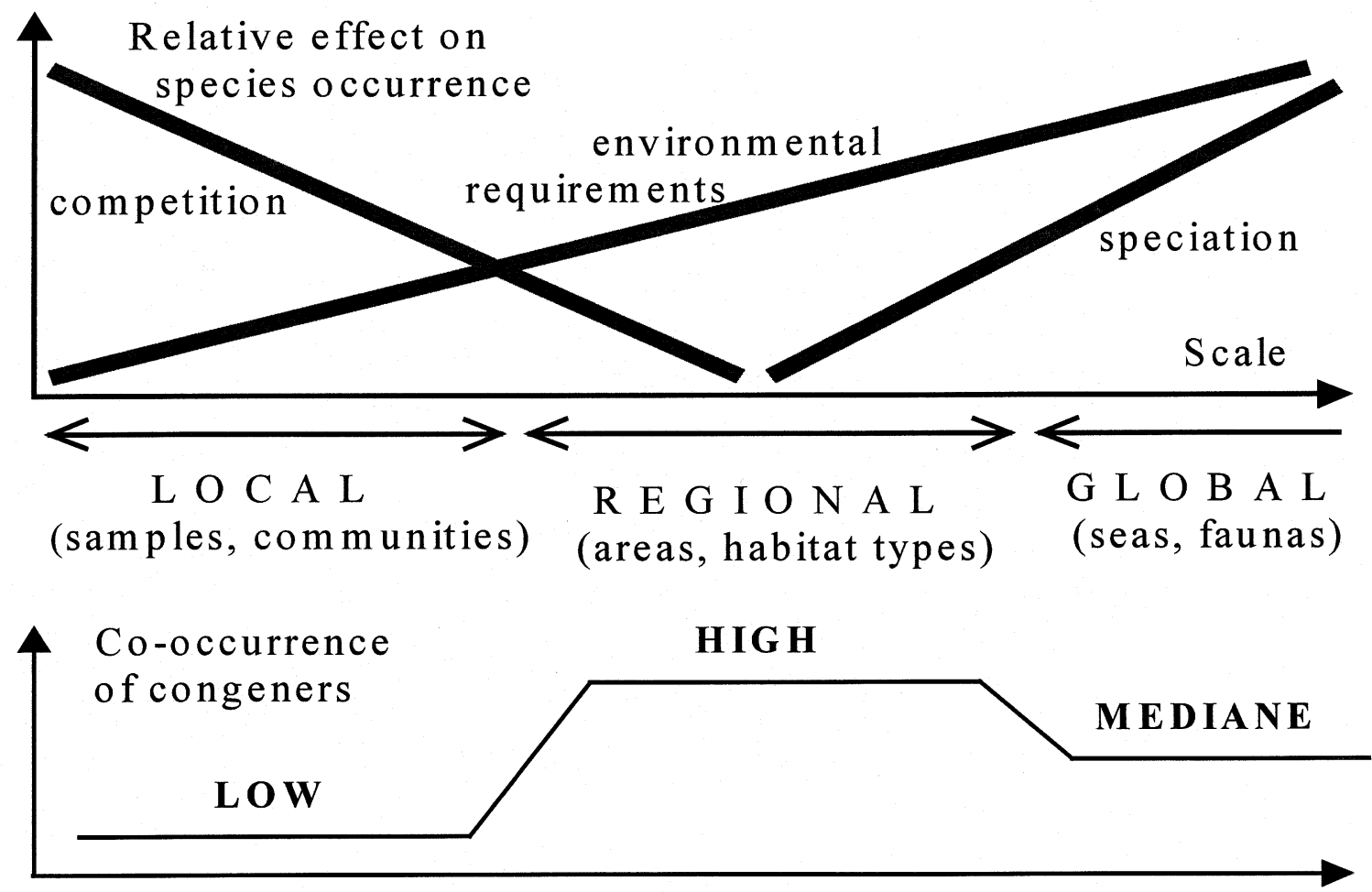

Fig. 6. Comparative role of ecological factors influencing species occurrence at different spatial scale (schematically, changed from Azovsky 1992). 
Table 1. Reciprocal scaling of temporal and spatial ranges for ecological hierarchies: $[$ Time $]=a[\text { Space }]^{D}$

\begin{tabular}{lccc}
\hline Type of hierarchy & Slope of regression, $D$ & Coeff. of correlation, $r$ & Data sources \\
\hline Landscape elements for boreal forests & 0.523 & 0.984 & Holling 1992 \\
Syntaxons of marine benthos & 0.547 & 0.983 & Original \\
Carbon/biomass dynamics in landscape & 0.683 & 0.868 & King 1991 \\
Ecological decisions made by birds & 0.724 & 0.975 & Holling 1992 \\
Vegetation patterns & 0.819 & 0.988 & Urban et al. 1987 \\
Scales of variability of ocean plankton & 1.260 & 0.902 & Haury et al. 1978 \\
Patchiness and turbulence in waters & 1.800 & 0.972 & Bowden 1970 \\
Ecological processes in phytoplankton & 2.000 & $*$ & Harris 1986 \\
Vegetation patches and gaps & 1.667 & $*$ & Urban et al. 1987 \\
Succession stages of forest parcels & 2.793 & 0.962 & Smirnova et al. 1990 \\
\hline
\end{tabular}

* Regressions or slopes were published without primary data.

relations. For quite different systems, no matter what their nature, criteria for organization and construction principles are, the data fit well to the power relation:

$$
[\mathrm{T}]=a[\mathrm{~L}]^{D}
$$

where $[\mathrm{T}]$ and $[\mathrm{L}]$ are average temporal and spatial scales for individual entities of different levels. Thus, for various hierarchical biosystems, there is the universal relation between size of certain structure and its characteristic time of development. Similar relations are known for developing systems from physics and economy, with every dynamical process resulting in its own specific scaling constant, from 2 for random dispersal or diffusion processes to 1 for direct transfer (Table 2). Smaller values are typical only of cooperative self-organized systems (Hastings and Sugihara 1993). One example is so-called "blow-up" processes of self-organization in dissipative structures (Kurdiumov 1990).

Now, look at the scaling parameter $D$ measuring the ratio between time and space in our case. We can see that the plankton systems related with water masses have intermediate values between 1 and 2 (Table 1, middle panel). Is this an intrinsic property or does it reflect the physical peculiarity of water environment? - the question is still open.
In contrast, all terrestrial and benthic hierarchies, which are surface-contact systems, have values less than one. I assume that this indicates a significant coherence of structure-generating processes in lower-level units. Finally, for the units of one and the same organization level, scaling values are significantly higher and close to 2 (diffusive dynamics) or more (rigid spatial limitation) (examples are at the bottom panel). Thus, the development of many ecological structures looks dynamically like diffusion or gradual growth, but their putting in the higher-level order is a qualitative leap forward and demands some cooperative organizational process. We can only speculate as yet on its reasons and nature, but the prospects here seem really exciting.

\section{Final conclusions}

Almost all ecological systems show significant variability on a range of scales. From this obvious fact it follows that to choose some single scale most appropriate for the study is sometimes important, but insufficient and often may be impossible. To outline the whole picture one should look for general regularities at multiple scales. I presented here only few examples of such a cross-scaling approach. I use

Table 2. Scaling parameter (time/space ratio) characteristic for pattern-generating processes of different nature.

\begin{tabular}{lll}
\hline Value & Type of process & Examples \\
\hline 2 & Diffusion-like processes & $\begin{array}{l}\text { Diffusion, stochastic propagation, } \\
\text { random-walk migrations }\end{array}$ \\
1 & $\begin{array}{l}\text { Direct (deterministic) } \\
\text { transfer processes }\end{array}$ & $\begin{array}{l}\text { Matter flows, simple growth, } \\
\text { directed migration }\end{array}$ \\
$<1$ & $\begin{array}{l}\text { Synergetic (cooperative) } \\
\text { processes, coherence }\end{array}$ & $\begin{array}{l}\text { Synergetic development, } \\
\text { turbulence, self-exciting growth }\end{array}$ \\
\hline
\end{tabular}


them to illustrate a variety of ways to search for apparently simple "scaling rules" for patterns in multiple dimensions, like space, time, organization and body size. Discovering uniformly scaled patterns, of course, is only the first step toward understanding them. The next step is to explain what causes and generates these regularities. And here it may be a long way toward the future progress.

Acknowledgements - I thank V. Mokievsky for stimulating discussions. This work was supported by the Russian Fund for Basic Researches (grants No. 97-05-64059 and 99-05-69639).

\section{References}

Azovsky, A. I. 1992. Co-occurrence of congener species of marine ciliates and the Competitive Exclusion principle: the effect of scale. - Russian J. Aquat. Ecol. 1: 49-59.

Azovsky, A. I. 1996. The effect of scale on congeners coexistence: can mollusks and polychaetes reconcile beetles to ciliates? Oikos 77: 117-126.

Azovsky, A. I. and Mokievsky, V. O. 1996. Studying the marine communities: perspective problems and problematic perspectives - plenary lecture. - In: 31st Eur. Mar. Biol. Symp., St. Petersburg, 9-13 Sept. 1996. St. Petersburg, pp. 27-28.

Azovsky, A. I. and Chertoprood, M. V. 1997. Analysis of spatial organization of communities and fractal structure of littoral benthos. - Rep. of Russ. Acad. Sci., Ser. Biol. 356: 713-715, in Russian.

Azovsky, A. I. and Chertoprood, M. V. 1998. Scale-oriented approach to the analysis of spatial structure of communities. Zhurnal Obshej Biologii (J. General Biol.) 59: 117-136, in Russian.

Azovsky, A. I. et al. 2000. Fractal properties of spatial distribution of intertidal benthic communities. - Mar. Biol., in press.

Bowden, K. F. 1970. Turbulence II. - Oceanogr. Mar. Biol. Ann. Rev. 8: 11-32.

Burkovsky, I. V., Azovsky, A. I. and Mokievsky, V. O. 1994. Scaling in benthos: from macrofauna to microfauna. - Arch. Hydrobiol. (Suppl.) 99: 517-535.

Chertoprood, M. V. and Azovsky, A. I. 2000. Scale-dependent spatial heterogeneity of the White Sea littoral macrofauna. Zhurnal Obshej Biologii (J. General Biol.) 60, in press.

Connor, E. F. and Bovers, M. A. 1987. The spatial consequences of interspecific competition. - Ann. Zool. Fenn. 24: 213226.

Den Boer, P. J. 1985. Exclusion, competition or coexistence? A question of testing the right hypotheses. - Z. Zool. Syst. Evolutionforsch. 23: 259-274.

Fenchel, T. 1993. Are there more small than large species? Oikos 68: 375-378.

Finlay, B. J., Esteban, G. F. and Fenchel, T. 1996. Global diversity and body size. - Nature 338: 132-133.

Finlay, B. J. et al. 1999. Global distribution of free-living microbial species. - Ecography 22: 138-144.

Gause, G. F. 1934. The struggle for existence. - Williams and Wilkins, Baltimore.

Harris, G. P. 1986. Phytoplankton ecology: structure, function and fluctuation. - Chapman and Hall.

Hastings, H. M. and Sugihara, G. 1993. Fractals: a user's guide for the natural sciences. - Oxford Univ. Press.
Haury, L. R., Mc Govan, J. S. and Wiebe, P. 1978. Patterns and processes in the time-space scales of plankton distributions. In: Steele, J. (ed.), Spatial pattern in plankton communities. Plenum Press, pp. 277-327.

Holling, C. S. 1992. Cross-scale morphology, geometry, and dynamics of ecosystems. - Ecol. Monogr. 62: 447-502.

King, A. W. 1991. Translating models across scales in the landscape. - In: turner, M. G. and Gardner, R. H. (eds), Quantitative methods in landscape ecology. Springer, pp. 479-517.

Kolasa, J. 1989. Ecological systems in hierarchical perspective: breaks in community structure and other consequences. Ecology 70: 36-47.

Kolasa, J. and Pickett, S. T. A. 1991. Heterogeneity in ecological systems. - Ecol. Studies 86, Springer.

Kurdiumov, S. P. 1990. Evolution and self-organization laws in complex systems. - Int. J. Modern Physics 1: 1-23.

Levin, S. A. 1992. The problem of pattern and scale in ecology.Ecology 73: 1943-1967.

MacArthur, R. H. 1968. The theory of the niche. - In: Levontin, R. C. (ed.), Population biology and evolution. Syracuse Univ. Press, Syracuse, pp. 159-176.

May, R. M. 1994. Biological diversity: differences between land and sea. - Philos. Trans. R. Soc. Lond. B 343: 105-111.

McGowan, J. A. 1971. Oceanic biogeography of the Pacific. - In: Funnell, B. M. and Riedel, W. R. (eds), Micropaleontology of Oceans. Cambridge Univ. Press, pp. 3-74.

O’Neill, R. V. et al. 1986. A hierarchical concept of ecosystems. Princeton Univ. Press.

Peters, R. H. 1983. The ecological implications of body size. Cambridge Univ. Press.

Peterson, D. L. and Parker, V. T. 1998. Ecological scale: theory and applications. - Columbia Univ. Press.

Shneider, D. C. 1994. Quantitative ecology: spatial and temporal scaling. - Academic Press.

Smirnova, O. V. et al. 1990. Population organization of vegetation cover of forests. - Puschino, in Russian.

Tchesunov, A. V. 1981. Zoogeographical distribution patterns of aquatic free-living nematodes. - In: Platonova, T. A. and Tsalolikhin, S. Y. (eds), Evolution, taxonomy, morphology and ecology of freeliving nematodes. - Leningrad, pp. 8895, in Russian.

Thorson, G. 1958. Parallel level-bottom communities, their temperature adaptation, and their "balance" between predators and food animals. - In: Buzzati-Traverso, A. A. (ed.), Perspectives in marine biology. Univ. of California Press, pp. 67-86.

Urban, D. L., O’Neill, R. V. and Shugart, H. H. 1987. Landscape ecology. - BioScience 37: 119-127. 